\title{
MICROSTRUCTURAL DEGRADATION OF CMSX-4: KINETICS AND EFFECT ON MECHANICAL PROPERTIES
}

\author{
Alexander Epishin ${ }^{1}$, Thomas Link ${ }^{1}$, Mohamed Nazmy $^{2}$, Marc Staubli ${ }^{2}$, Hellmuth Klingelhöffer ${ }^{3}$, Gert $_{\text {Nolze }}^{3}$ \\ ${ }^{1}$ Technical University Berlin, Institute for Materials Science and Technologies, Berlin D10587, Germany \\ ${ }^{2}$ ALSTOM Ltd., Department of Materials Technology, TTTM, Baden CH5401, Switzerland \\ ${ }^{3}$ Federal Institute for Materials Research and Testing, Berlin D12205, Germany
}

Keywords: Microstructural Degradation, Tensile Properties, LCF

\begin{abstract}
The $\gamma / \gamma^{\prime}$-microstructure of nickel-base superalloys gradually degrades during high temperature loading which deteriorates the mechanical properties. In the work presented the kinetics of microstructural degradation of the superalloy CMSX-4 was investigated metallographically in a wide parameter field $(T, \sigma, t)$. The effect of microstructural degradation on mechanical properties was determined by mechanical testing of specimens pre-annealed under load. The laboratory results were compared with the microstructure of ex-service blades of CMSX-4.
\end{abstract}

\section{Introduction}

Nickel-base superalloys used as blade material for gas turbines are strengthened by small intermetallic $\gamma$ '-precipitates of the $\mathrm{Ni}_{3} \mathrm{Al}$ type. The $\gamma^{\prime}$-precipitation provides excellent mechanical properties at high temperatures but its efficiency strongly depends on size and morphology of the $\gamma^{\prime}$-precipitates. During high temperature service in aircraft and power gas turbines the $\gamma / \gamma^{\prime}$ microstructure of nickel-base superalloys gradually degrades, i.e. coarsens and becomes rafted [e.g. 1,2]. This degradation of the microstructure deteriorates the mechanical properties [e.g. 3-6]. Therefore for a reliable prediction of the blade lifetime the microstructural degradation of the material has to be taken into account. This is one goal of the European Action COST 538 "High Temperature Plant Lifetime Extension" (2004-2008) in frame of which the presented work was performed. The COST 538 activities include investigations of the kinetics of microstructural degradation, the effect of microstructural degradation on mechanical properties and modeling of the mechanical behavior considering the microstructure. The high temperature material investigated by our group is the singlecrystal nickel-base superalloy CMSX-4 widely used in gas turbine industry. The present paper reports on the experimental results of our activities, the microstructurally-based mechanical model based on these results is presented in [7].

\section{Experimental}

The characterization of the microstructural degradation in a wide parameter field (temperature $T$, stress $\sigma$, time $t$ ) typical for the service conditions of turbine blades is extremely material and time consuming. Therefore a new experimental technique was introduced: repeated load annealing of Flat Wedge shaped (FW) specimens. The geometry of the specimen differs from the conventional rod shaped specimens under two aspects. Firstly, the flat surfaces allow to observe the microstructure non-destructively after removing the surface layer and thus to continue the mechanical test after the metallographic investigation. This procedure saves not only specimens but also testing time because the starting time of test number $n$ is the total time of the proceeding $(n-1)$ tests. Secondly, it has a wedge shape, thus the stress changes linearly along the specimen axis. The specimen gage length is $50 \mathrm{~mm}$ within which the specimen width changes from $6 \mathrm{~mm}$ up to $10 \mathrm{~mm}$, i.e. the cross-section area $S$ changes by the shape factor $S F=S_{\max } / S_{\min }=10 / 6=1.67$. Hence, one specimen is sufficient to cover a whole range of times and stresses. The initial thickness of the FW specimen is $10 \mathrm{~mm}$. After each load annealing (called degradation) the specimen was grinded and polished for SEM investigation, which reduces it thickness by 1 $\mathrm{mm}$. The test series was terminated when the specimen thickness was reduced down to $5 \mathrm{~mm}$, i.e. the applied procedure allowed to perform up to 5 successive degradation experiments accompanied by metallographic analysis of the evolving microstructure. Experimental details of this technique are presented in [8].

The FW specimens of CMSX-4 were annealed under constant load at different temperatures in the range of $850-1050^{\circ} \mathrm{C}$. The load at each temperature was chosen in such a way, that the stress in the thinnest cross-section $\sigma_{\max }(T)$ corresponds to rupture after $10000 \mathrm{~h}$. The lifetime of $10000 \mathrm{~h}$ is close to what is required for gas turbine aeroengines in civil aircrafts. The stress $\sigma_{\min }(T)$ in the thickest cross-section is given by $\sigma_{\min }(T)=\sigma_{\max }(T) / S F$. The total testing time was up to several thousand hours. The degradation conditions of the FW specimens are listed in Table 1. Additionally three cylindrical specimens were degraded at $1050^{\circ} \mathrm{C} / 68$ $\mathrm{MPa} / 1500 \mathrm{~h}, 950^{\circ} \mathrm{C} / 110 \mathrm{MPa} / 8760 \mathrm{~h}$ and $850^{\circ} \mathrm{C} / 230 \mathrm{MPa} / 11175$ h.

Table 1. Degradation conditions of FW specimens.

\begin{tabular}{|c|c|c|c|c|c|c|c|}
\hline $\begin{array}{c}\text { Spec. } \\
\text { No. }\end{array}$ & $\mathrm{T},{ }^{\circ} \mathrm{C}$ & $\begin{array}{c}\sigma_{\min }-\sigma_{\max }, \\
\mathrm{MPa}\end{array}$ & \multicolumn{5}{|c|}{ Accumulated time $t, \mathrm{~h}$} \\
\hline 1 & 1050 & $56-94$ & 25 & 75 & 175 & 375 & 775 \\
\hline 2 & 1000 & $72-120$ & 50 & 150 & 350 & 750 & 1550 \\
\hline 3 & 950 & $97-162$ & 100 & 300 & 700 & 1500 & 3100 \\
\hline 4 & 950 & $155-259$ & 100 & 300 & $\begin{array}{c}572 \\
\text { rupture }\end{array}$ & - & - \\
\hline 5 & 900 & $137-228$ & 200 & 600 & 1400 & 3000 & 6200 \\
\hline 6 & 850 & $200-334$ & 500 & 1500 & 3500 & 7500 & - \\
\hline
\end{tabular}

The investigation of the $\gamma / \gamma^{\prime}$-microstructure was performed in a SEM with a computer controlled stage, which allows to position easily the SEM frame within the specimen gage at defined locations corresponding to certain stress levels. The kinetics of the microstructural degradation was characterized qualitatively by observing the transition of the $\gamma$ '-morphology from cuboidal to rafted shape. In addition, the increase of the $\gamma$-channel width $w$ 
and of the microstructure period $\lambda^{[001]}=\left(\gamma\right.$-width $+\gamma^{\prime}$-width $)$ along the load axis [001] were measured. The main parameter is the channel width $w$, because it provides a measure of the degree of rafting (see below) and the Orowan back stress. The Orowan stress is important for the plastic deformation of the $\gamma$-matrix. The microstructure period $\lambda^{[001]}$ is relevant, because it characterizes the global coarsening of $\gamma / \gamma^{\prime}$-microstructure. The images were processed by the line section method using the software a4i, Olympus [9]. In order to minimize the scatter of the results due to the dendritic inhomogeneity, all images were taken in the same area of the dendrite, namely the secondary dendrite arms representing most of the material.

The second type of mechanical tests were sequential experiments: first degradation, then either tensile or low cycle fatigue (LCF) testing. The degradation was performed at different temperatures between $850^{\circ} \mathrm{C}$ and $1100^{\circ} \mathrm{C}$. After degradation the specimen surface was grinded to remove the oxide layer, which could influence the results of the second test. The tensile tests were performed at temperatures within the interval $20-950{ }^{\circ} \mathrm{C}$ with a strain rate of about $5 \% / \mathrm{min}$. The LCF tests were carried out under completely reversed strain controlled cyclic loading at the temperatures 700,750 and $950^{\circ} \mathrm{C}$.

Small, un-cooled ex-service blades of CMSX-4, which passed $12700 \mathrm{~h}$ of operation in a small industrial gas turbine, were used as case study. The investigation included the metallographic inspection of different parts of the blades as well as room temperature tensile tests of mini specimens excised from these blades.

\section{Results}

\section{Kinetics of rafting}

The large scatter of the results did not allow an unambiguous identification of a specific growth function $w=f_{w}(t)$. Therefore as a first approximation a linear function was used. However, from the data obtained it follows that a single straight line could not fit the whole time range, which is not surprising, since two successive processes govern degradation. At the beginning the dominant process is rafting [e.g. 10, 11]. Here the $\gamma$-channels parallel to the load direction become narrow and disappear, the perpendicular channels widen. This results in the formation of rafted $\gamma / \gamma^{\prime}$-microstructure where the $\gamma^{\prime}$-rafts are separated by $\gamma$ channels much wider than the initial channel width $w_{0}$. The kinetics of rafting of the cuboidal $\gamma / \gamma$-microstructure was characterized by the widening rate $\dot{w}_{c u b}$ of the perpendicular channels. After rafting has completed the second process becomes dominant, namely coarsening of the rafted microstructure controlled by the migration of $\gamma$ '-terminations according to the Graham-Kraft model [12]. The kinetics of coarsening of the rafted $\gamma / \gamma$-microstructure was characterized by the channel widening rate $\dot{w}_{\text {raft }}$. Fig. 1a shows the increase of channel width in CMSX4 during load annealing at $950^{\circ} \mathrm{C}$ and $110 \mathrm{MPa}$. The dependence $w=f_{w}(t)$ is fitted by two straight lines with the slopes $\dot{w}_{c u b}$ and $\dot{w}_{\text {raft }}$. It is seen that the widening rate slows down after rafting is completed $\left(\dot{w}_{\text {plate }}<\dot{w}_{c u b}\right)$, which in agreement with the wellknown fact that the plate-like microstructure is more stable than the cuboidal one [e.g. 13].
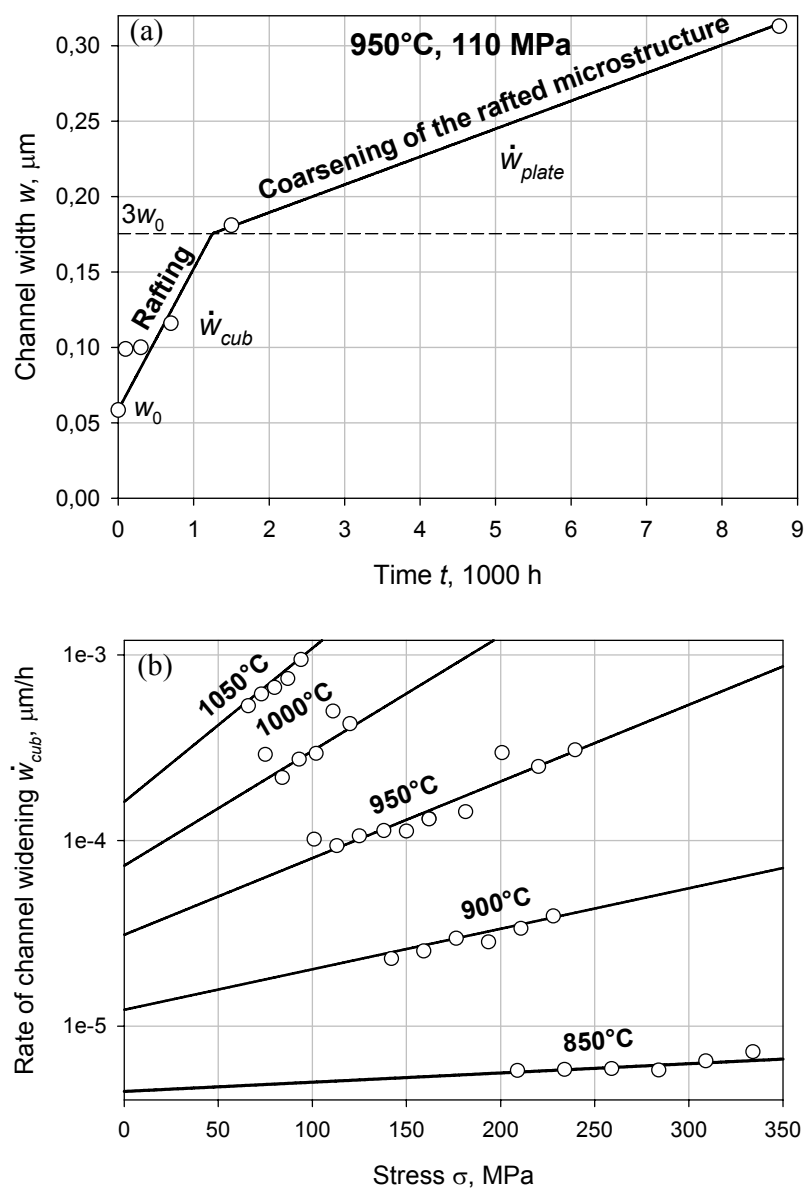

Fig. 1. The kinetics of widening of $\gamma$-channels in [001] singlecrystals of CMSX-4.

(a) - Increase of the channel width $w$ during load annealing at $950^{\circ} \mathrm{C}, 110 \mathrm{MPa}$.

(b) - Widening rate during rafting $\dot{w}_{c u b}$ as a function of temperature and stress.

The transition from rafting to coarsening has been determined by defining a fixed ordinate $w=w_{\text {raft }}$, where rafting is completed and then fitting the time of rafting $t_{\text {raft }}$ and the slopes of the lines. $w_{\text {raft }}$ was calculated according to geometrical considerations [14]

$$
w_{\text {raft }}=c \cdot w_{0}
$$

with

$$
c=\frac{\lambda_{\text {raft }}^{[001]}}{\lambda_{0}^{\langle 001\rangle}} \frac{1-V_{\text {raft }}^{\prime}}{1-\sqrt[3]{V_{0}^{\prime}}}
$$

where, $\quad \lambda_{0}^{[001]}=\lambda^{[001]}(t=0) \quad$ and $\quad \lambda_{\text {raft }}^{[001]}=\lambda^{[001]}\left(t_{\text {raft }}\right)$ are the microstructure periods at start and end of rafting, $V_{0}^{\prime}=V^{\prime}(t=0)$ and $V_{r a f t}^{\prime}=V^{\prime}\left(t_{r a f t}\right)$ the corresponding $\gamma^{\prime}$-volume fractions. From our measurements it follows that $\lambda^{[001]}$, characterizing the global coarsening of the microstructure according to LSW-mechanism, did not change remarkably during rafting. Under the degradation conditions used here (Table 1) the ratio $\lambda_{\text {raft }}^{[001]} / \lambda_{0}^{[001]}$ was in the 
range 1-1.2. The volume fraction remained constant too $V_{0}^{\prime} \approx V_{\text {raft }}^{\prime} \approx 0.73$. In this case formula (3) gives $c \approx 3$, which allows to formulate a simple criterion for the end of the rafting process: rafting ends when the channel width $w$ achieves $3 w_{0}$. This " $3 w_{0}$-criterion" is in agreement with our metallographic observations.

The dependence of the widening rate $\dot{w}_{c u b}$ on $T$ and $\sigma$ is shown in Fig. 1b. These results were fitted by the Arrhenius formula for processes activated by temperature and stress:

$$
\dot{w}_{c u b}(T, \sigma)=A \cdot \exp \left[-\frac{Q-U(T) \cdot \sigma}{R T}\right]
$$

where $A$ is a pre-exponential factor, $Q$ the activation energy, $R$ the universal gas constant and $U(T)$ the temperature dependent activation volume described by a power function $U(T)=U_{T}\left(T-T_{0}\right)^{n}$ for $T>T_{0}$. The fitted parameters $A=9.31 \cdot 10^{4}$ $\mu \mathrm{m} / \mathrm{h}, Q=221780 \mathrm{~J} / \mathrm{mol}, U_{T}=0.19 \mathrm{~J} /\left(\mathrm{mol} \cdot \mathrm{MPa} \cdot \mathrm{K}^{\mathrm{n}}\right), T_{0}=1100.7 \mathrm{~K}$ $\left(827.7^{\circ} \mathrm{C}\right), n=1.294$ are temperature and stress independent. Comparison of the experimental points for $\dot{w}_{c u b}$ with the fitting curves (Fig. 1b) shows good agreement.

From the " $3 w_{0}$-criterion" follows:

$$
t_{\text {raft }} \approx 2 w_{0} / \dot{w}_{c u b}
$$

which allows to predict the rafting time $t_{\text {raft }}$ as:

$$
t_{\text {raft }}(T, \sigma) \approx \frac{2 w_{0}}{A} \cdot \exp \left[\frac{Q-U(T) \cdot \sigma}{R T}\right]
$$

The shape of the function $t_{\text {raft }}=f_{t}(T, \sigma)$ with the obtained fit parameters $A, Q, U_{T}, T_{0}, n$ is shown in Fig. 2.

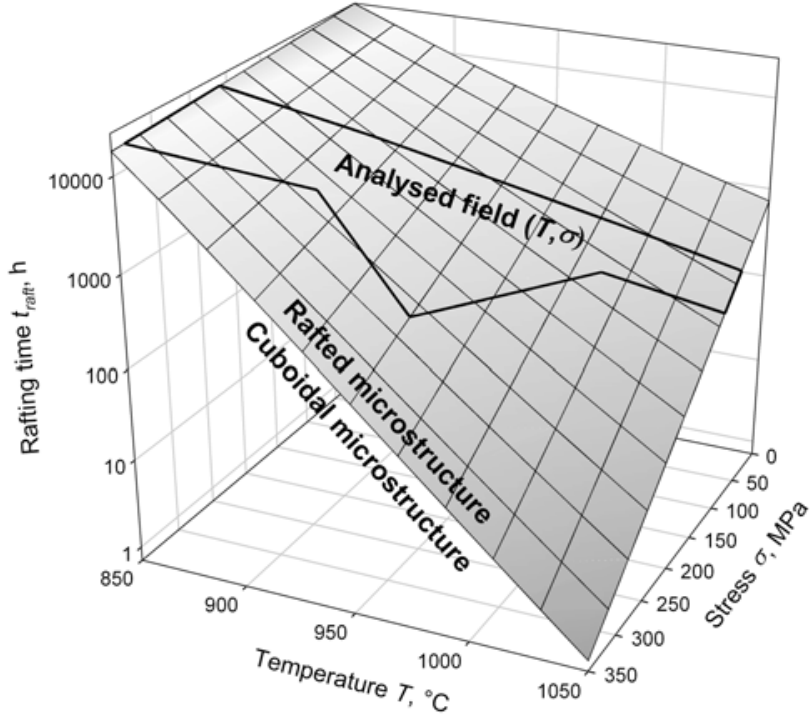

Fig. 2. Time for complete raft formation as a function of temperature and stress. The solid line shows the $(T, \sigma)$-field of the degradation experiments.

\section{Effect of degradation on tensile properties}

It was found that at all investigated temperatures $\left(20-950^{\circ} \mathrm{C}\right)$ the degradation generally deteriorates the tensile properties, i.e. decreases the yield stress (YS) and the ultimate tensile stress
(UTS). Figs 3a and b show the effect of degradation on the shape of the tensile stress-strain diagrams at room temperature and $950^{\circ} \mathrm{C}$ respectively. It is seen that in both cases the degradation changes the stress-strain curves and these changes are stronger for higher degradation temperatures. The first important change is a decrease in YS, which is especially pronounced at room temperature. After $1050^{\circ} \mathrm{C} / 68 \mathrm{MPa} / 2500 \mathrm{~h}$ degradation $\mathrm{YS}$ at $20^{\circ} \mathrm{C}$ decreases from $952 \mathrm{MPa}$ down to $630 \mathrm{MPa}$, so $34 \%$. The effect of this degradation on YS at $950^{\circ} \mathrm{C}$, as shown in Fig. $3 \mathrm{~b}$, is essentially smaller, about $18 \%$. It is remarkable that at room temperature the degraded material shows work hardening, i.e. an ascending stress-strain curve in the region of plastic flow (Fig. 3a), while at $950^{\circ} \mathrm{C}$ degradation has the opposite effect (Fig. 3b). The consequence of this work softening at $950^{\circ} \mathrm{C}$ is a reduction in UTS, e.g. after $1050^{\circ} \mathrm{C} / 68 \mathrm{MPa} / 2500 \mathrm{~h}$ degradation from 891 $\mathrm{MPa}^{1}$ down to $678 \mathrm{MPa}$, so $24 \%$. Thus degradation reduces UTS at high temperatures, whereas at lower temperatures the deteriorative effect on YS is stronger.
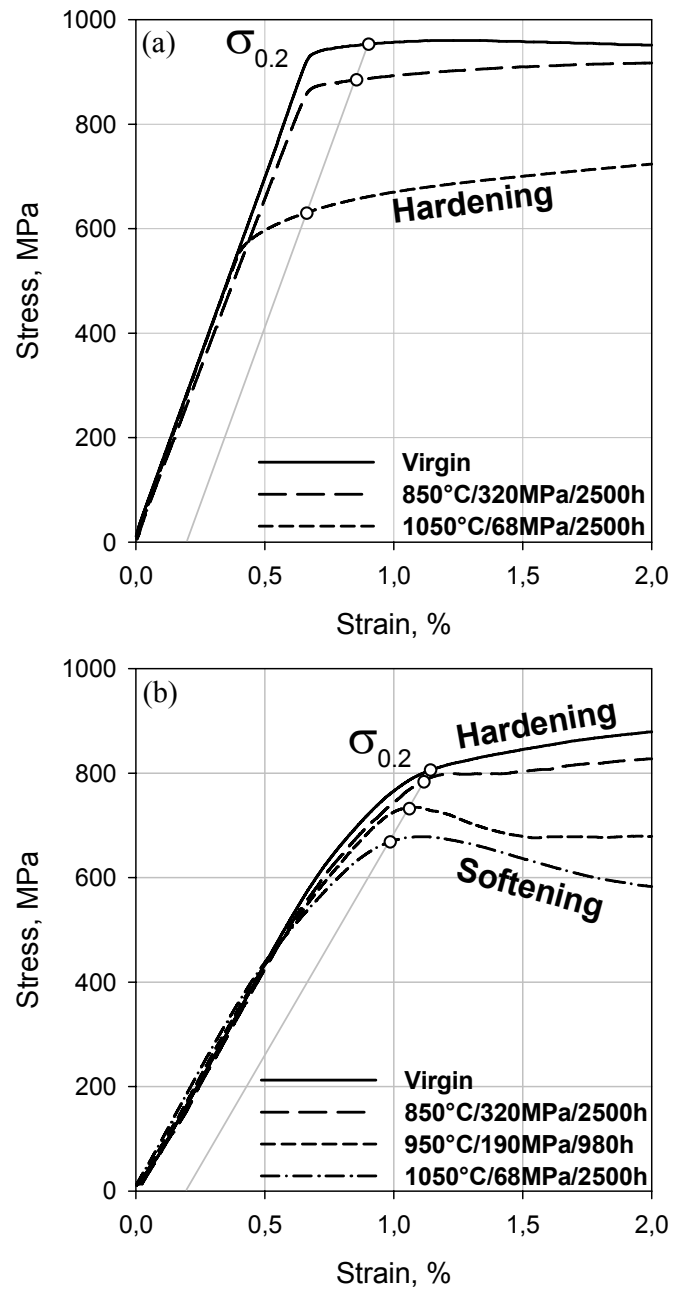

Fig. 3. The initial parts of tensile curves (up to $2 \%$ strain) for virgin and degraded material. The degradation conditions are marked in the graphics.

(a)- Tensile tests at room temperature.

(b) - Tensile tests at $950^{\circ} \mathrm{C}$.

\footnotetext{
${ }^{1}$ Maximum on the stress-strain curve for virgin material is out of the $2 \%$-strain range presented in Fig. $3 b$.
} 


\section{Effect of degradation on LCF behaviour}

CMSX-4 degraded at $1100^{\circ} \mathrm{C} / 90 \mathrm{MPa}$ showed in strain controlled LCF tests at $700^{\circ} \mathrm{C}$ with a strain amplitude $\Delta \varepsilon / 2=0.625 \%$ that even after a short degradation time of about $100 \mathrm{~h}$ the number $N$ of cycles to failure decreased by a factor of about 8 . From the creep curves recorded during the degradation tests follows that $100 \mathrm{~h}$ correspond to the end of primary creep. Metallographic inspection of the degraded specimens shows that at this time the $\gamma$ '-raft formation is completed. After the rafted structure has formed $N$ retains almost constantly this low level until the end of secondary creep, which corresponds to $1800 \mathrm{~h}$ for these degradation conditions.
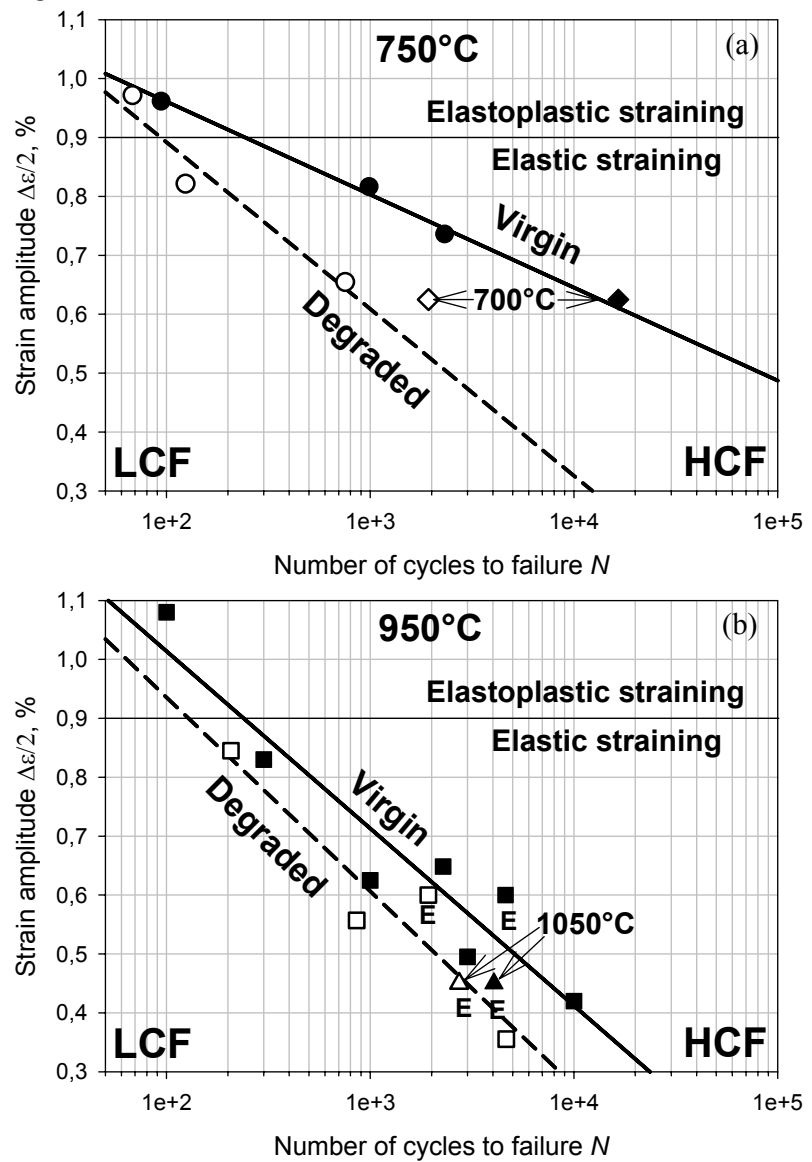

Fig. 4. Effect of degradation on the number of cycles to failure $N$ under cyclic, strain controlled loading $\left(R_{\varepsilon}=-1\right)$ at $750^{\circ} \mathrm{C}$ (a) and $950^{\circ} \mathrm{C}(\mathrm{b})$. Black symbols and solid lines correspond to virgin material, white symbols and dashed lines to degraded material. For comparison few additional points are included. In (a) for $700^{\circ} \mathrm{C}$ from our experiments. In (b) from experiments of the University Erlangen-Nürnberg [4], marked by "E". They were measured either at $950^{\circ} \mathrm{C}$ or at $1050^{\circ} \mathrm{C}$.

Fig. 4 shows the effect of degradation at 1050 or $1100^{\circ} \mathrm{C}$ on the LCF lifetime, with LCF tests performed at $700-1050^{\circ} \mathrm{C}$ and strain amplitudes $0.3-1.1 \%$. The presented data were mostly obtained in this work and partially taken from literature. It follows that the effect of degradation on LCF is much stronger at the lower LCF test temperature $750^{\circ} \mathrm{C}$ (Fig. 4a) and weaker at the higher temperature $950^{\circ} \mathrm{C}$ (Fig. 4b). At these low temperatures the degradation effect becomes pronounced when the strain amplitude $\Delta \varepsilon / 2$ is smaller than the elasticity limit for virgin CMSX-4, about $0.9 \%$ in the temperature range $700-1050^{\circ} \mathrm{C}$ (horizontal lines in Figs $4 a, b$ ). Fitting the black symbols (virgin material) with straight lines shows, that the virgin material is more sensitive to fatigue at $950^{\circ} \mathrm{C}$ than at $750^{\circ} \mathrm{C}$ and the sensitivity is expected to be stronger for high cycle fatigue (HCF). This is a remarkable difference to the degraded material, which has almost the same LCF behavior for the investigated test temperatures.

\section{$\underline{\text { Ex-service blade }}$}

As a case study, small un-cooled solid blades of CMSX-4 were investigated after $12700 \mathrm{~h}$ service in a small industrial gas turbine. The $\gamma / \gamma^{\prime}$-microstructure of the blade was investigated in different longitudinal sections and some results are presented in Fig. 5

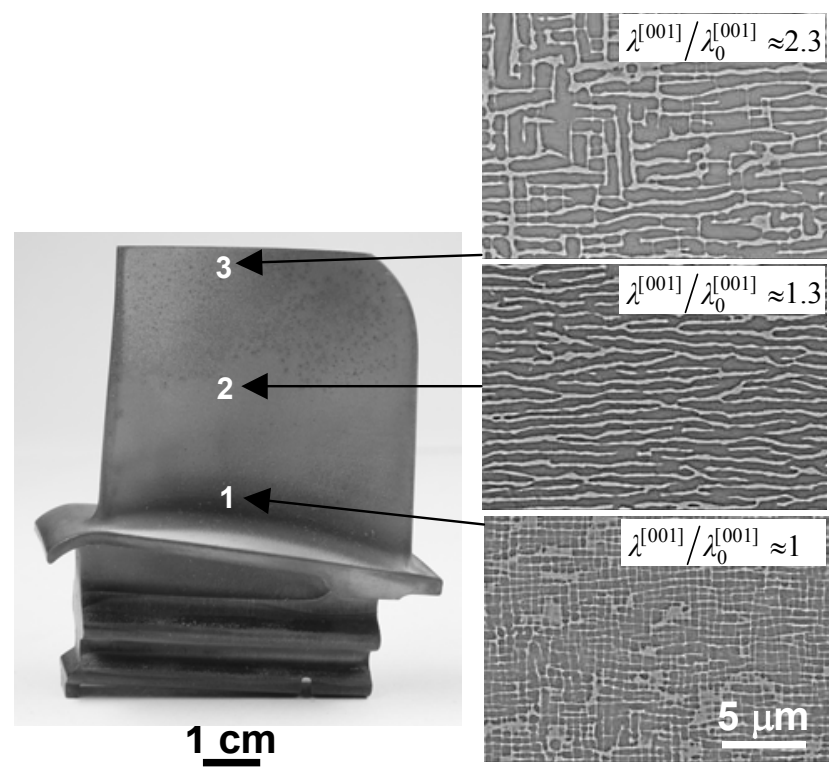

Fig. 5. A blade of CMSX-4 and $\gamma / \gamma^{\prime}$-microstructure of blade material after service.

The $\gamma / \gamma^{\prime}$-microstructure near the blade platform (position 1 in Fig. 5) retained the initial condition, i.e. it remains cuboidal with the same period, $\lambda^{[001]} / \lambda_{0}^{[001]} \approx 1$, as one could expect from the local operation parameters $800^{\circ} \mathrm{C} / 190 \mathrm{MPa}$. In the blade middle (position $2,920^{\circ} \mathrm{C} / 110 \mathrm{MPa}$ ) the microstructure is completely rafted and somewhat coarsened, $\lambda^{[001]} / \lambda_{0}^{[001]} \approx 1.3$. The $\gamma^{\prime}$-rafts are long and always oriented perpendicular to the blade axis. In the blade tip (position $3,980^{\circ} \mathrm{C} / 30 \mathrm{MPa}$ ) the microstructure is also rafted but the $\gamma^{\prime}$-rafts are thicker and shorter than in the blade middle. Most of the $\gamma^{\prime}$-rafts are perpendicular to the blade axis but in some areas they are oriented along the blade axis. In the blade tip the microstructure is obviously coarsened. The measurement gives an increase of the microstructure period by a factor of about 2.3. The observed morphological changes generally fit with formula (5), which predicts for the considered service conditions no rafting near the blade platform and complete rafting in the blade middle and top. Cylindrical mini specimens $(2 \mathrm{~mm}$ in 
diameter) were cut from the central part of blade, where temperature and stress were about $920^{\circ} \mathrm{C} / 110 \mathrm{MPa}$, and tested for tension at room temperature. The tests gave yield stress of about $840 \mathrm{MPa}$, which is about $13 \%$ lower than that for virgin material (952 MPa)

\section{Discussion}

The kinetics of the microstructural degradation of CMSX-4 was characterized by the widening of the $\gamma$-channels similar to the approach used in [15]. The analytical description of the results obtained in a wide parameter field $(T, \sigma, t)$ made it possible to derive a formula for the evaluation of the rafting time $t_{\text {raft }}$ (5) based on the " $3 w_{0}$-criterion" for the end of rafting. The function $t_{\text {raft }}=f_{t}(T, \sigma)$ has similarity with the well-known Larson-Miller dependence $p(\sigma)=T(C+\log t)$, allowing to calculate creep rupture lifetime $t$ as a function of temperature $T$ and stress $\sigma$. This is not surprising, because creep and microstructure evolution are closely connected. Both dependencies $t_{\text {raft }}=f_{t}(T, \sigma)$ and $p(\sigma)=T(C+\log t)$ follow from the generalized Arrhenius formula describing the kinetics of temperature activated processes under stress.

The " $3 w_{0}$-criterion", used to calculate $t_{\text {raft }}$, assumes that the microstructure period $\lambda^{[001]}$ does not change significantly during rafting, which is valid for the analyzed parameter field $(T, \sigma, t)$. This hypothesis works satisfyingly for stresses above a certain level as in the case of the lower and middle parts of the investigated blades, where $\lambda^{[001]} / \lambda_{0}^{[001]} \leq 1.3$. The fact, that e.g. in the blade middle the microstructure period $\lambda^{[001]}$ increased by the factor 1.3 does not necessarily mean, that here the " $3 w_{0}$ criterion" can not be applied, because the time for rafting, $t_{\text {raft }} \sim 100 \mathrm{~h}$ (see Fig. 1a), is much shorter than $12700 \mathrm{~h}$ and therefore the microstructure period $\lambda_{\text {raft }}^{[001]}\left(t_{\text {raft }}\right)$ is smaller than $\lambda^{[001]}(12700 \mathrm{~h})$. For very low stresses however the rafting process is very slow and therefore there is time enough for the cuboidal microstructure to coarsen significantly before the cuboids coalesce, which results in a clear increase of $\lambda^{[001]}$. This is typical for the parts of the blade where temperatures are high but stresses very low, e.g. for the tip of the blade (see Fig. 5 left-top), where $\lambda^{[001]} / \lambda_{0}^{[001]}$ was found to be significantly larger, about 2.3. For such a special degradation condition the " $3 w_{0}$-criterion" and consequently formula (5) have be modified by taking into account the change of $\lambda^{[001]}$ but this requires additional investigations at very low stress levels. The $\gamma^{\prime}$-coarsening during rafting is considered in [16].

In our work degradation means load annealing. The explanation of the observed reduction of YS, especially at room temperature, is not simple, because several microstructural changes taking place, namely $\gamma$-channel widening, loss of interfacial coherency, coalescence of the $\gamma^{\prime}$-cubes and a topological inversion ${ }^{2}$. To identify the relevant mechanism, comparison with degradation caused by load free annealing [e.g. 18-20] could be helpful. Here

\footnotetext{
${ }^{2} \gamma$ '-phase forms junctions and becomes the matrix [17]
}

a very similar reduction in YS was found but of course without rafting and topological inversion. So it can be concluded that the global coarsening of the microstructure, characterized by the increase of $\lambda^{[001]}$, and the loss of coherency, measured e.g. by the increase of the $\gamma / \gamma^{\prime}$-misfit $\delta$, are the decisive factors. However a physical explanation of the reduction of YS observed at low temperatures as well as the material softening at high temperatures is not possible without detailed investigations of the deformation mechanisms, which are temperature and stress dependent.

The decisive factor for LCF strength however is rafting. It is well known that the fatigue strength of plate-like structures is lower under cyclic loading including tension perpendicular to the plate plane. The reason for this effect is the fast growth of fatigue cracks along the interface between the plates, which is generally weaker than the bulk material. Such a material behavior is reported for the superalloy CMSX-2 [3], where the growth rate of fatigue cracks was found to increase by several times when the material becomes rafted. The preferable crack growth along the extended $\gamma / \gamma^{\prime}$-interfaces was confirmed metallographically $[4,5]$. So from general considerations about plate-like structures and the results above [3-5] it is reasonable to assume that for the LCF properties of superalloys the relevant point is the $\gamma^{\prime}$-morphology, cuboidal or rafted. This is confirmed by our finding that after primary creep at $1100^{\circ} \mathrm{C}$, so when rafting is completed, the number of cycles to failure has strongly decreased, but then remains nearly constant until the end of secondary creep.

Two questions regarding the results presented in Fig. 4 are not quite clear:

1. Why is the rafting effect on LCF pronounced only at the low temperatures $700^{\circ} \mathrm{C}$ and $750^{\circ} \mathrm{C}$ and diminishes at the high temperatures $950^{\circ} \mathrm{C}$ and $1050^{\circ} \mathrm{C}$ ?

2. Why does the difference between virgin and degraded material strongly increase for low strain amplitudes, i.e. in the field of macroscopically elastic straining?

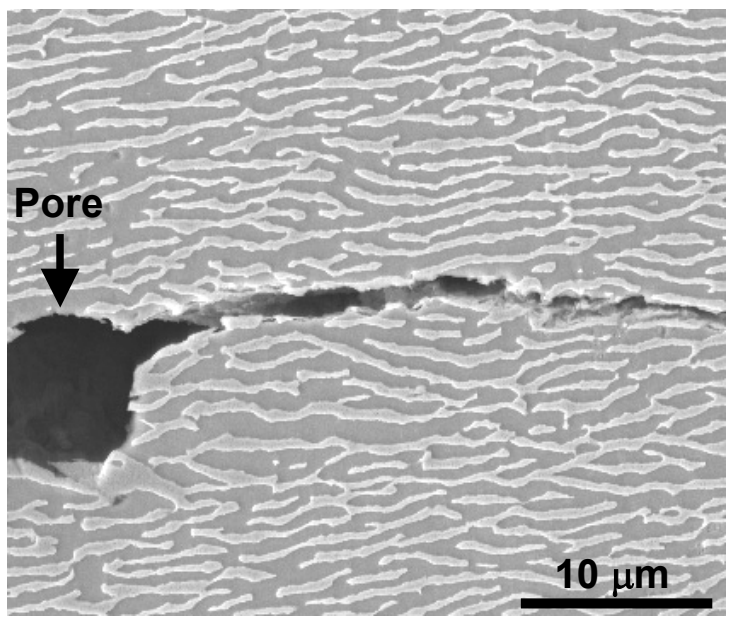

Fig. 6. Crack nucleation from a pore in pre-rafted CMSX-4 during LCF test at $700^{\circ} \mathrm{C}$.

The first question is difficult, because several material parameters as well as deformation mechanisms remarkably change in the considered temperature range $700-1050^{\circ} \mathrm{C}$. For example, when temperature rises from $700^{\circ} \mathrm{C}$ up to $1050^{\circ} \mathrm{C}$ the superalloy ductility increases by a factor of about 10 , while the YS and UTS 
significantly decrease. At lower temperatures the main mechanism of plastic deformation is gliding, at high temperatures climbing controlled creep is involved. For the second question an answer could be, that rafting has an even stronger effect on crack nucleation than on crack propagation. At small strain amplitudes $\Delta \varepsilon / 2$ when most of the material deforms elastically without damage the decisive factor for the fatigue lifetime becomes the local damage at structural inhomogeneities acting as stress concentrators. In single-crystal superalloys these critical defects are micropores, as could be shown by HIP (hot isostatical pressure) experiments. Fatigue tests performed under the conditions of macroscopically elastic straining $\left(700^{\circ} \mathrm{C}\right.$, $\left.\Delta \varepsilon / 2=0.625 \%, R_{\varepsilon}=-1\right)$ gave for the UNHIPPed specimen $16 \cdot 10^{3}$ cycles to failure, whereas the test of the HIPPed specimen was interrupted after $180 \cdot 10^{3}$ cycles (no rupture). It is reasonable to expect that in rafted material the extended incoherent raft interfaces which crop out the pore surface (Fig. 6) facilitate crack initiation and hereby reduce fatigue lifetime.

\section{Conclusions}

The following conclusions can be drawn from this work:

1. For the first time the kinetics of the microstructural degradation of CMSX-4 could be characterized in a wide field of $(T, \sigma, t)$ and described analytically. This was possible due to a new technique, namely repeated load annealing of flat wedge shaped (FW) specimens. On the base of the obtained results a " $3 w_{0}$-criterion" for rafting was proposed and a formula for the rafting time derived.

2. The microstructural degradation of CMSX-4 results in a deterioration of the tensile properties: reduction of YS, pronounced at low temperatures, and material softening, pronounced at high temperatures. The effect on the tensile properties is stronger for higher degradation temperatures.

3. The deteriorative effect of degradation on LCF lifetime was found to be pronounced at the low temperatures 700 and $750^{\circ} \mathrm{C}$. The effect increases when lowering the strain amplitude $\Delta \varepsilon / 2$ down to the field of macroscopically elastic straining. Therefore it should be expected that this deterioration effect is stronger for HCF. For the fatigue lifetime mostly the change of the $\gamma^{\prime}-$ morphology (cuboidal $\rightarrow$ rafted) is important.

\section{Acknowledgements}

The authors thank Mr. T. May, Mr. M. Hill (TU Berlin), Ms. S. Schriever, Ms. C. Krimmling, Mr. R. Saliwan-Neumann and Ms. E. Hoffmann (BAM, Berlin) for assistance in performed investigation.

\section{References}

[1] N. Miura, N. Harada, Y. Kondo and T. Matsuo, Morphological changes in $\gamma^{\prime}$ phase in different portions of first stage high pressure turbine blade of PWA 1480, Proc. of the $7^{\text {th }}$ Conf. "Materials for Advanced Power Engineering", eds. J. Lecomte-
Beckers, M. Carton, F. Schubert and P. J. Ennis, Forschungszentrum Jülich, 2002, pp. 245-254.

[2] T. Link, A. Epishin and H. Klingelhöffer, Microstructural and mechanical degradation of CMSX-4 under creep conditions, Presentation at the COST 538 meeting in Cranfield, UK, 2007.

[3] S. H. Ai, V. Lupinc and G. Onofrio, Influence of precipitate morphology on high temperature fatigue crack growth of a single crystal nickel base superalloy, Scripta Metall. Mater., Vol. 29, 1993, pp. 1385-1390.

[4] M. Ott and H. Mughrabi, Dependence of the high-temperature low-cycle fatigue behaviour of the monocrystalline nickel-base superalloys CMSX-4 and CMSX-6 on the $\gamma / \gamma^{\prime}$-morphology, Mater. Sci. and Engineering A, Vol. 272, 1999, pp. 24-30.

[5] A. Epishin, T. Link, U. Brückner, H. Klingelhöffer and P. D. Portella, The effect of high temperature creep damage on low cycle fatigue of CMSX-4, Proc. of the $8^{\text {th }}$ Liege conf. "Materials for Advanced Power Engineering”, J. Lecomte-Beckers, M. Carton, F. Schubert and P. J. Ennis, eds., Forschungszentrum Jülich, 2006, pp. 317-325.

[6] M. Nazmy, A. Epishin, T. Link and M. Staubli, A Review of degradation in single crystal nickel based superalloys, Energy Materials, Vol. 1, 2006, No. 4, pp. 263-268.

[7] B. Fedelich, G. Künecke, A Epishin, T. Link and P. Portella, Constitutive modelling of creep degradation due to rafting in single crystal Ni-base superalloys, accepted for Creep 2008, Bayreuth, Germany.

[8] A. Epishin, T. Link, H. Klingelhöffer, B. Fedelich, U. Brückner and P. D. Portella, New technique for characterization of microstructural degradation under creep: Application to the nickel-base superalloy CMSX-4, accepted for Creep 2008, Bayreuth, Germany.

[9] Olympus, soft imaging system, www.soft-imaging.net

[10] F. R. N. Nabarro, Rafting in superalloys, Metall. Trans., Vol. 27A, 1996, pp. 513-529.

[11] N. Matan, D. C. Cox, C. M. Rae and R. C. Reed, On the kinetics of rafting in CMSX-4 superalloy single crystals, Acta mater., Vol. 47, 1999, pp. 2031-2045.

[12] L. D. Graham and R. W. Kraft, Coarsening of Eutectic Microstructures at Elevated Temperatures, Trans. Metall. Soc. A.I.M.E., Vol. 236, 1966, pp. 94-101.

[13] M. V. Nathal and R. A. MacKay, The Stability of Lamellar $\gamma$ $\gamma$ ' Structures, Mater. Eng., Vol. 85, 1987, pp. 127-138.

[14] DFG report PO 405/10-1, LI 494/4-1 "Microstructural degradation of the single-crystal superalloy CMSX-4 during annealing under load: Implementation of rafting kinetics in mechanical modelling”. BAM - TU Berlin, 2007.

[15] K. Serin, G. Göbenli and G. Eggeler, On the influence of stress state, stress level and temperature on $\gamma$-channel widening in 
the single crystal superalloy CMSX-4, Mater. Sci. Eng., A387390, 2004, pp. 133-137.

[16] W. Chen and J-P. Immarigeon, Thickening Behaviour of $\gamma^{\prime}$ Precipitates in Nickel Base Superalloys during Rafting, Scripta Mater., Vol. 39, 1998, pp. 167-174.

[17] A. Epishin, T. Link, U. Brückner and P. D. Portella, Kinetics of Topological Inversion of the $\gamma / \gamma^{\prime}$ Microstructure during High Temperature Creep of a Nickel-Base Superalloy, Acta Mater., Vol. 49, 2001, pp. 4017-4023.

[18] R.G. Davies and N.S. Stoloff, On the yield stress of aged NiAl alloy, Trans. AIME, Vol. 233, 1965, pp. 714-719.

[19] R.A. Stevens and P.E.J. Flewitt, The effect of the $\gamma^{\prime}$ precipitate coarsening during isothermal aging and creep of the Ni-base superalloy IN-738LC, Mater. Sci. Eng., Vol. 37, 1979, pp. 237-247.

[20] R. Sharghi-Moshtaghin and S. Asgari, The influence of thermal exposure on the $\gamma^{\prime}$ precipitates characteristics and tensile behavior of superalloy IN-738LC, J. of Material Processing Technology., Vol. 147, 2004, pp. 343-350. 